\title{
BMJ Open Metformin initiation and renal impairment: a cohort study in Denmark and the UK
}

\author{
Christian Fynbo Christiansen, ${ }^{1}$ Vera Ehrenstein, ${ }^{1}$ Uffe Heide-Jørgensen, ${ }^{1}$ \\ Stine Skovbo, ${ }^{1}$ Helene Nørrelund, ${ }^{1}$ Henrik Toft Sørensen, ${ }^{1}$ Lin Li, ${ }^{2}$ Susan Jick ${ }^{2}$
}

To cite: Christiansen CF, Ehrenstein V, HeideJørgensen U, et al. Metformin initiation and renal impairment: a cohort study in Denmark and the UK. BMJ Open 2015;5:e008531. doi:10.1136/bmjopen-2015008531

- Prepublication history for this paper is available online. To view these files please visit the journal online (http://dx.doi.org/10.1136/ bmjopen-2015-008531)

Received 17 April 2015 Revised 6 August 2015 Accepted 12 August 2015

CrossMark

\footnotetext{
${ }^{1}$ Department of Clinical Epidemiology, Aarhus University Hospital, Aarhus $N$, Denmark

${ }^{2}$ Boston Collaborative Drug Surveillance Program, Boston University School of Public Health, Lexington,

Massachusetts, USA
}

Correspondence to Dr Christian Fynbo Christiansen; cfc@clin.au.dk

\section{ABSTRACT}

Objectives: To estimate prevalence of renal impairment, rate of decline in kidney function and changes in metformin use after decline in kidney function, in metformin initiators.

Design, setting and participants: We conducted this 2-country cohort study using routine data from northern Denmark and the UK during 2000-2011. We included metformin initiators among patients aged $\geq 30$ years with medically treated diabetes.

Main outcome measures: We described patients' demographics, comorbidity, co-medications and their estimated glomerular filtration rates (eGFR).

Furthermore, we described the patients' characteristics according to eGFR level. Finally, we examined the rate of any decline in eGFR and changes in metformin use within 90 days after first decline in eGFR during follow-up.

Results: We included 124720 metformin initiators in the 2 countries. Prevalence of eGFR $<60 \mathrm{~mL} / \mathrm{min} /$ $1.73 \mathrm{~m}^{2}$ among metformin initiators was $9.0 \%$ in Denmark and $25.2 \%$ in the UK. In contrast, prevalence of eGFR values $<30 \mathrm{~mL} / \mathrm{min} / 1.73 \mathrm{~m}^{2}$ among metformin initiators was $0.3 \%$ in Denmark and $0.4 \%$ in the UK. Patients with renal impairment were older and more likely to have received cardiovascular drugs. Incidence rate of decline in renal function was 4.92 per 100 person-years ( $95 \% \mathrm{Cl} 4.76$ to 5.09$)$ in Denmark and 7.48 per 100 person-years ( $95 \% \mathrm{Cl} 7.39$ to 7.57 ) in the UK. The proportion of patients continuing metformin use, even after a first decline brought the eGFR below $30 \mathrm{~mL} / \mathrm{min} / 1.73 \mathrm{~m}^{2}$, was $44 \%$ in Denmark and $62 \%$ in the UK. There was no clinically significant dose reduction with decreasing baseline eGFR level discernible from the data.

Conclusions: Mild to moderate renal impairment was common among metformin initiators, while severe renal impairment was uncommon. Patients with severe renal impairment frequently continued receiving/ redeeming metformin prescriptions even 90 days after eGFR decline.

\section{INTRODUCTION}

Metformin was approved in Europe in the 1950 s for treatment of type 2 diabetes. ${ }^{12}$

\section{Strengths and limitations of this study}

- The study describes metformin initiators in a large population of patients with medically treated diabetes.

- The study includes comparable and complementary data from electronic databases in two European Union member states: Denmark and the UK.

- The data include comprehensive individual-level prescription data, laboratory data and data on medical history, all linked at the individual level.

- Some misclassification may arise from the use of automated prescription and dispensation data to assess initiation and continuation of metformin.

While metformin is a first-line treatment, it is contraindicated in patients with certain acute and chronic conditions-such as severe infections, cardiac or respiratory failure, shock, or chronic renal or hepatic dysfunction-because of the feared, although not convincingly demonstrated, risk of lactic acidosis. ${ }^{3-7}$

Because metformin is eliminated through renal excretion, ${ }^{8}$ patients with renal impairment may be vulnerable to its side effects. Current guidelines recommend cautious use of metformin in patients with renal impairment, and metformin is contraindicated in patients with severe renal impairment. ${ }^{4}$ Guidelines recommend discontinuation of metformin in patients with an estimated glomerular filtration rate (eGFR) below $30 \mathrm{~mL} / \mathrm{min} / 1.73 \mathrm{~m}^{2}$; but recommended eGFR thresholds that should trigger cautious use and dose reduction, but not discontinuation, vary between 60 and $45 \mathrm{~mL} / \mathrm{min} /$ $1.73 \mathrm{~m}^{2} .^{24}{ }^{9-11}$ Reported prevalence of eGFR below $60 \mathrm{~mL} / \mathrm{min} / 1.73 \mathrm{~m}^{2}$ among metformin users ranges from $4.5 \%$ to $25 \%,{ }^{12-17}$ with most evidence originating from studies that were small, ${ }^{12-14} 17$ hospital-based ${ }^{12}{ }^{17}$ or restricted to patients with poorly controlled 
diabetes. ${ }^{12}$ Given the lack of clear-cut recommendations, the observed utilisation patterns and the limitations of previous studies, the use and safety of metformin in patients with renal impairment should be further examined in a population-based setting among a broad range of patients with diabetes.

This study was commissioned by the European Medicines Agency (EMA) with the goal of assessing the utilisation of metformin in patients with and without renal insufficiency in current clinical practice in at least two European Union Member States. The study was undertaken to inform potential reassessment and unified recommendations by the regulator of guidelines for metformin use in patients with renal impairment. In a series of epidemiological analyses among patients with pharmacologically treated diabetes, we examined (1) prevalence of renal impairment and other contraindications among metformin initiators, (2) characteristics of metformin initiators by stage of renal impairment, (3) rate of decline in renal function and (4) utilisation of metformin after worsening of renal impairment.

\section{PATIENTS AND METHODS}

\section{Study design and inclusion period}

We undertook a cohort study including metformin initiators in northern Denmark and in the UK. The inclusion period was defined based on data availability in northern Denmark (including 2000-2010 in the former counties of Aarhus and North Jutland, 2007-2010 in the former county of Ringkjobing, 2009-2012 in the former county of Viborg), and in the UK (including 2000-June 2011).

\section{Source population and data sources}

The source population for the study was residents of northern Denmark and the UK-the two EU Member States with relevant routine databases. In Denmark, we individually linked data from four registries using the unique personal identification number assigned at birth or on immigration, by the Danish Central Personal Registry. ${ }^{18} 19$ This registry, covering the entire Danish population, has recorded vital status and migrations of Danish residents since 1968. We obtained data from the Aarhus University Prescription Database (AUPD) on reimbursed prescriptions for antidiabetic and other drugs dispensed in the community outpatient pharmacies of northern Denmark. ${ }^{20}$ Data on creatinine, blood glucose and glycated haemoglobin (HbAlc) were obtained from the Danish Laboratory Information System for the North and Central Denmark (LABKA) database, ${ }^{21}$ which tracks all hospital-based laboratory tests in the study region, including those sent to hospital laboratories by general practitioners (GPs). The Danish National Registry of Patients ${ }^{22}$ provided data on comorbidities and prevalence of contraindications. This registry covers the entire Danish population and has registered hospitalisations since 1977 and outpatient visits since 1995. Up to 20 discharge diagnoses are recorded for each hospital contact, using the International Classification of Diseases, Eighth revision (ICD-8) until 1994 and the ICD-10 thereafter.

In the UK, the source population was restricted to eligible patients treated by GPs participating in the Clinical Practice Research Datalink (CPRD). ${ }^{23}{ }^{24}$ The CPRD is an ongoing longitudinal database that has collected data from over 500 general practices in the UK since 1987. It covers approximately eight million individuals $(\sim 6 \%$ of the UK population), whose age and sex distribution is representative of the UK population. We accessed the database through the Boston Collaborative Drug Surveillance Program (BCDSP). The BCDSP has received anonymised raw data generated by the GPs since the CPRD was first established. Validation studies have shown greater than $90 \%$ concordance between information from the original paper records and information recorded on the computer file. Further, the indication for newly prescribed drugs is recorded more than $95 \%$ of the time. ${ }^{23}$ The CPRD data housed at the BCDSP are updated annually, so that the most recent data available are never more than 15 months out-of-date. The data are recorded using multiple data screens or files, including registration, drug, laboratory data, event files and files containing additional clinical details.

\section{Study population}

The study population of metformin initiators was derived from a cohort of persons aged 30 years or older at study start, with medically treated diabetes, as defined by at least one prescription for an antidiabetic medication during the study period. The study population was restricted to patients aged 30 years or older to avoid, to the extent possible, inclusion of patients with metformintreated polycystic ovary syndrome (PCOS) or type 1 diabetes, both of which are frequently diagnosed before age 30 years. ${ }^{25}{ }^{26}$ In addition, we excluded patients with a diagnosis of type 1 diabetes in the UK, while the ICD-10 coding in Denmark did not allow clear distinction between diabetes types. The study was also restricted to patients with at least 1 year of prescription history before cohort entry, in order to allow for an observable washout period to define new users. In addition, we required patients to have at least one measurement of serum creatinine $\left(\mathrm{S}_{\mathrm{cr}}\right)$ on or before cohort entry in order to assess baseline renal function. Patients were followed from day of first metformin prescription until death, emigration, end of enrolment in a CPRD practice (the UK only), or end of follow-up on 31 December 2011 in Denmark and 30 June 2012 in the UK.

\section{Use of metformin and other antidiabetic agents}

Metformin users were identified from records of issued prescriptions provided by GPs in the UK and from outpatient-dispensed prescriptions in Denmark. We identified all patients with at least one prescription for 
metformin during the study period, but included only metformin initiators in the analyses. ${ }^{27}$ Metformin initiators were defined as patients with no prescriptions for metformin within a washout period of 365 days before the first metformin prescription during the study period.

The cohort entry (start of follow-up) was the date of the first new metformin prescription during the study period. For each patient with at least two prescriptions for metformin, we estimated the mean daily dose at cohort entry as the ratio of the total amount of metformin dispensed at cohort entry to the number of days until the second metformin dispensation. We estimated the mean daily dose during the follow-up using the cumulative prescribed dose dispensed from all prescriptions during the follow-up divided by the number of days of use. To estimate the last day of use in the UK, we calculated the length of the last metformin prescription in the follow-up using the amount dispensed in the last issued prescription divided by the prescribed daily dose whenever available. Otherwise, we assumed that the last filled metformin prescription in the follow-up covered a period corresponding to the mean duration of all metformin prescriptions in the data set, that is, 43 days in Denmark and 42 days in the UK.

We defined discontinuation after an eGFR decline as presence of a metformin prescription within 90 days before the date of the eGFR decline combined with absence of a metformin prescription within 90 days after the date of the eGFR decline in patients without rebound in eGFR level within this 90-day period. We defined switching as a prescription for a non-metformin antidiabetic drug within 90 days after the date of persistent eGFR decline, with no metformin prescription recorded within this 90-day time window. Patients were considered to have stopped metformin before a persistent eGFR decline if the last prescription prior to the eGFR ended more than 90 days before the date of the decline. Patients with fewer than 90 days of follow-up after the date of persistent eGFR decline were categorised as having incomplete follow-up.

\section{Renal function and renal impairment}

For each patient, we identified all recorded $\mathrm{S}_{\mathrm{cr}}$ laboratory values in the LABKA database in Denmark ${ }^{21}$ and in the CPRD's laboratory file. We did not include measurements during hospital inpatient admissions, to avoid confounding by acute illness. Creatinine values were used to assess renal function in the calculation of the $\mathrm{eGFR}^{28}$ at baseline and during follow-up. We used the four-item Modification of Diet in Renal Disease (MDRD) equation, which estimates eGFR based on $\mathrm{S}_{\mathrm{cr}}$ age, race and sex. ${ }^{28}{ }^{29}$ Because neither study database collects data on race, the eGFR calculation assumed Caucasian race for all persons in the study, as they represent the majority of Danish and UK residents. Based on eGFR, kidney function was classified as follows, in accordance with the criteria for chronic kidney disease:
eGFR $\geq 60 \mathrm{~mL} / \mathrm{min} / 1.73 \mathrm{~m}^{2}$ (corresponding to stage 1 and 2 chronic kidney disease or normal renal function); eGFR $45-59 \mathrm{~mL} / \mathrm{min} / 1.73 \mathrm{~m}^{2}$ (stage $3 \mathrm{a}$ chronic kidney disease); eGFR $30-44 \mathrm{~mL} / \mathrm{min} / 1.73 \mathrm{~m}^{2}$ (stage $3 \mathrm{~b}$ chronic kidney disease); eGFR $15-29 \mathrm{~mL} / \mathrm{min} / 1.73 \mathrm{~m}^{2}$ (stage 4 chronic kidney disease) and eGFR $<15 \mathrm{~mL} /$ $\min / 1.73 \mathrm{~m}^{2}$ (stage 5 chronic kidney disease).

\section{Covariates}

We identified the following characteristics from the available data sources: age at cohort entry; sex; HbAlc level measurement within 12 months before cohort entry; time from the first recorded antidiabetic drug prescription until the cohort entry date, as a proxy for diabetes duration in Denmark, or time from either the first recorded antidiabetic drug prescription or first recorded diabetes diagnosis, whichever was earlier, until cohort entry in the UK (categorised as first prescription, $<1$; 1 to $<3$; $3+$ years); history of potential contraindications for metformin within 5 years before cohort entry, including diagnoses of diabetic ketoacidosis, liver disease and alcohol-related diseases; history of other chronic diseases within up to 5 years before cohort entry, including each of the conditions in the Charlson Comorbidity Index (except for diabetes and diabetes with organ complications); ${ }^{30} 31$ and concomitant use (within 90 days before cohort entry) of other antidiabetic medications, non-steroidal anti-inflammatory drugs (NSAIDs), antihypertensives or aspirin (acetylsalicylic acid).

\section{Statistical analyses}

First, we described characteristics, including eGFR level, of the metformin initiators at cohort entry (see table 1 for the list of characteristics).

Second, we described the patient characteristics according to the five categories of chronic renal disease at cohort entry. Third, we assessed the rate of first decline in eGFR level following patients from first new metformin prescription until first decline in eGFR, emigration or death, whichever came first.

Fourth, we assessed continued use and discontinuation of metformin within 90 days after the first decline in eGFR, from the baseline eGFR (based on last available outpatient $S_{\text {cr }}$ measurement within 1 year before or on the cohort entry date), excluding patients with rebound in eGFR level during the 90-day period after first decline. Both study sites used SAS statistical software V.9 (Cary, North Carolina, USA) for data management and analyses.

\section{RESULTS}

\section{Characteristics of metformin initiators}

The study included 22728 metformin initiators in Denmark and 101992 metformin initiators in the UK. Table 1 provides characteristics of metformin initiators in Denmark and the UK. The median age was 61 years 
Table 1 Renal impairment and other characteristics of metformin initiators during the study period

\begin{tabular}{|c|c|c|}
\hline & $\begin{array}{l}\text { Northern Denmark } \\
\mathrm{N}=22728\end{array}$ & $\begin{array}{l}\text { UK } \\
N=101992\end{array}$ \\
\hline \multicolumn{3}{|l|}{ eGFR (most recent within a year before cohort entry)-n (\%) } \\
\hline$\geq 60 \mathrm{~mL} / \mathrm{min} / 1.73 \mathrm{~m}^{2}$ & 20677 (90.98) & 76304 (74.81) \\
\hline $45-59 \mathrm{~mL} / \mathrm{min} / 1.73 \mathrm{~m}^{2}$ & $1576(6.93)$ & $20648(20.24)$ \\
\hline $30-44 \mathrm{~mL} / \mathrm{min} / 1.73 \mathrm{~m}^{2}$ & $410(1.80)$ & $4620(4.53)$ \\
\hline $15-29 \mathrm{~mL} / \mathrm{min} / 1.73 \mathrm{~m}^{2}$ & $61(0.27)$ & $408(0.40)$ \\
\hline$<15 \mathrm{~mL} / \mathrm{min} / 1.73 \mathrm{~m}^{2}$ & $4(0.02)$ & $12(0.01)$ \\
\hline Metformin daily dose $(\mathrm{mg})$ at cohort entry, mean $(\mathrm{SD})^{\star}$ & $1433.53(2410.20)$ & $1104.63(426.64)$ \\
\hline Metformin daily dose during follow-up (mg), mean (SD)* & $1387.37(539.86)$ & $1265.86(634.70)$ \\
\hline \multicolumn{3}{|l|}{ Demographics at cohort entry } \\
\hline Age (years)-median (IQR) & $61(51-69)$ & $63(54-72)$ \\
\hline \multicolumn{3}{|l|}{ Age (years) -n (\%) } \\
\hline 30-39 & $1639(7.21)$ & $4542(4.45)$ \\
\hline $40-49$ & $3186(14.02)$ & 12566 (12.32) \\
\hline $50-59$ & 5572 (24.52) & 23228 (22.77) \\
\hline $60-69$ & $6895(30.34)$ & 29098 (28.53) \\
\hline $70-79$ & 3971 (17.47) & 23507 (23.05) \\
\hline$\geq 80$ & $1465(6.45)$ & $9051(8.87)$ \\
\hline Female gender-n (\%) & $10269(45.18)$ & $45361(44.48)$ \\
\hline Male gender-n (\%) & 12459 (54.82) & $56631(55.52)$ \\
\hline \multicolumn{3}{|l|}{ Duration of type 2 diabetes at cohort entryt-n (\%) } \\
\hline First prescription at cohort entry & $21799(95.91)$ & $18766(18.40)$ \\
\hline$<1$ year & $55(0.24)$ & 32868 (32.23) \\
\hline $1-3$ years & $220(0.97)$ & $19211(18.84)$ \\
\hline$\geq 3$ years & $654(2.88)$ & 31147 (30.54) \\
\hline $\mathrm{HbA} 1 \mathrm{c}$ at cohort entry, \%, mean (SD) (a) & $8.09(1.91)$ & $8.67(1.80)$ \\
\hline \multicolumn{3}{|c|}{ History of potential contraindications for metformin within 5 years before cohort entry-n (\%) } \\
\hline Diabetic ketoacidosis & $10(0.04)$ & $69(0.07)$ \\
\hline Liver disease & $215(0.95)$ & $1034(1.01)$ \\
\hline Alcohol-related diseases & $128(0.56)$ & $1070(1.05)$ \\
\hline \multicolumn{3}{|l|}{ Co-medication within 90 days before cohort entry-n (\%) } \\
\hline Other antidiabetic medications & $738(3.25)$ & $20141(19.75)$ \\
\hline NSAIDs & $3802(16.73)$ & 11965 (11.73) \\
\hline Antihypertensives & $11878(52.26)$ & $64112(62.86)$ \\
\hline Aspirin & $982(4.32)$ & 28954 (28.39) \\
\hline \multicolumn{3}{|l|}{ Charlson Comorbidity Index Score at cohort entry-n (\%) (a) } \\
\hline 0 & $16196(71.26)$ & $57993(56.86)$ \\
\hline 1 & 3754 (16.52) & $24592(24.11)$ \\
\hline 2 & $1781(7.84)$ & $11870(11.64)$ \\
\hline 3 & $585(2.57)$ & $4704(4.61)$ \\
\hline$\geq 4$ & $412(1.81)$ & $2833(2.78)$ \\
\hline \multicolumn{3}{|l|}{ Lifestyle factors at cohort entry (where available) } \\
\hline Obesity & NA & $54100(53.04)$ \\
\hline \multicolumn{3}{|l|}{ Smoking } \\
\hline Current & NA & $17505(17.16)$ \\
\hline Former & NA & $41660(40.85)$ \\
\hline Never & NA & $40957(40.16)$ \\
\hline Missing & NA & $1870(1.83)$ \\
\hline
\end{tabular}

(IQR 51-69) in Denmark and 63 years (IQR 54-72) in the UK. There was no clinically important difference in mean HbAlc between countries.

The overall mean daily dose of metformin at cohort entry was $1433 \mathrm{mg}$ in Denmark and $1105 \mathrm{mg}$ in the UK.
The prevalence of diabetic ketoacidosis, liver disease or alcohol-related diseases was low. Most patients had no major comorbidity, as indicated by a Charlson Comorbidity Index Score of 0 (71.3\% in Denmark and $56.9 \%$ in the UK; table 1 ). 
The proportion of patients with chronic kidney disease (eGFR values below $60 \mathrm{~mL} / \mathrm{min} / 1.73 \mathrm{~m}^{2}$ ) was $9.0 \%$ in Denmark and $25.2 \%$ in the UK (table 1 ). The proportion of patients with a baseline eGFR level below $30 \mathrm{~mL} / \mathrm{min} / 1.73 \mathrm{~m}^{2}$ was $0.3 \%$ in Denmark and $0.4 \%$ in the UK (table 1).

\section{Characteristics of metformin initiators according to eGFR level}

The proportion of metformin initiators using other concurrent antidiabetic medication, mainly sulfonylureas, was higher in the UK than in Denmark, and increased with decreasing eGFR levels in both countries. We observed no substantial decrease in mean daily metformin dose with decreasing eGFR at cohort entry. NSAIDs were prescribed in more than $10 \%$ of patients within 90 days before cohort entry, even in patients with low baseline eGFR levels (table 2).

\section{Decline in eGFR and metformin use}

Among the 22728 metformin initiators in Denmark, 3434 had a decline in eGFR level during 69792 personyears (mean follow-up 3.1 years; table 3). Among the 101992 metformin initiators in the UK, 27325 had a decline in eGFR within 365208 person-years (mean follow-up 3.6 years). The corresponding incidence rates were 4.92 (95\% CI 4.76 to 5.09) per 100 person-years in Denmark and 7.48 (7.39 to 7.57 ) per 100 person-years in the UK.

Most patients continued metformin use within 90 days after a persistent decline in eGFR from $\geq 60$ to $45-59 \mathrm{~mL} / \mathrm{min} / 1.73 \mathrm{~m}^{2}: 70.4 \%$ in Denmark and $84.7 \%$ in the UK (table 4). Even when the first decline during follow-up was to an eGFR below $30 \mathrm{~mL} / \mathrm{min} / 1.73 \mathrm{~m}^{2}$, $44 \%$ (45 out of 103) of metformin users in Denmark and $62 \%$ (281 out of 450 ) in the UK had a prescription for metformin within 90 days after the decline date (cumulated proportion across baseline levels $\geq 30 \mathrm{~mL}$ / $\mathrm{min} / 1.73 \mathrm{~m}^{2}$ in table 4$)$.

\section{DISCUSSION}

Among metformin initiators in Denmark and in the UK, we identified a considerable number of patients with baseline eGFRs below $45 \mathrm{~mL} / \mathrm{min} / 1.73 \mathrm{~m}^{2}$, in particular in the UK. However, few metformin initiators had eGFRs below the absolute contraindicated eGFR of $30 \mathrm{~mL} /$ $\min / 1.73 \mathrm{~m}^{2}$. Among the few metformin users whose eGFR dropped below $30 \mathrm{~mL} / \mathrm{min} / 1.73 \mathrm{~m}^{2}, 44 \%$ in Denmark and $62 \%$ in the UK continued metformin within 90 days after the decline.

The study included virtually complete unselected population-based data from a well-defined geographical area in Denmark and a representative sample of general practices in the UK. At the same time, although the laboratory data were virtually complete, estimation of eGFR depends on steady-state $S_{\text {cr }}$ level, which is difficult to assess from routine records. Exclusion of inpatient laboratory test results reduced the potential impact of a severe acute illness on eGFR values. Minor misclassification of eGFR cannot be ruled out after the implementation of standardised creatinine measurement in some laboratories during the later years of the study period. Missing data on race may have led us to underestimate eGFR in the expected few non-Caucasian patients included. A further limitation was the need to restrict the study population to persons with a baseline creatinine value, since availability of baseline creatinine values may correlate with frequency of medical contacts. According to the guidelines, however, patients with diabetes should have their creatinine measured at least once yearly, independent of antidiabetic treatment, and we therefore expect that most patients with diabetes were included. Finally, we used dispensations of antidiabetic drugs in the Danish data as a proxy for a diabetes diagnosis since there are no GP diabetes diagnoses in the Danish data. However, some patients may have been diagnosed with type 2 diabetes earlier than the dispensation date, and, thus, we may have underestimated diabetes duration in some patients. In addition, using a single prescription for an antidiabetic drug may have led to inadvertent inclusion of patients with prediabetes, those with metformin-treated PCOS and, in Denmark, even some with type 1 diabetes, into the study population. However, this contamination is unlikely to be severe, given that $95.8 \%$ of patients in the UK data had a diagnosis of type 2 or unspecified diabetes before or at cohort entry. The prevalence of PCOS without diabetes at metformin initiation was low (1.6\% in Denmark and $0.9 \%$ in the UK), and contraindications for metformin use are expected to be similar in patients with PCOS as those in patients with type 2 diabetes. Based on the available data, duration of diabetes was estimated differently in the CPRD, where outpatient diagnoses enable identification of both date of the first diabetes diagnosis and date of the first diabetes treatment. This may explain the longer observed mean diabetes duration among the UK patients.

Our finding that a considerable proportion of metformin initiators had some renal impairment, confirms results from previous smaller studies and suggests that our findings are applicable to other European countries. A Scottish study of 11297 metformin users from a diabetes register found that as many as $25 \%$ of the users had an eGFR of $<60 \mathrm{~mL} / \mathrm{min} / 1.73 \mathrm{~m}^{2}$, including $14 \%$ with eGFR $50-59 \mathrm{~mL} / \mathrm{min} / \mathrm{m}^{2}, 8.5 \%$ with eGFR $40-49 \mathrm{~mL} / \mathrm{min} / 1.73 \mathrm{~m}^{2}$ and $2.8 \%$ with an eGFR of $30-39 \mathrm{~mL} / \mathrm{min} / 1.73 \mathrm{~m}^{2} .{ }^{15}$ In other smaller studies, the proportion of metformin users with eGFR $<60 \mathrm{~mL} / \mathrm{min}$ / $1.73 \mathrm{~m}^{2}$ was consistent across geographic regions, study designs and types of diabetic population: $17 \%$ among 558 hospitalised patients with poorly regulated diabetes in Poland; ${ }^{12} 18 \%$ among women and $13 \%$ among men in a randomised trial of glycaemic optimisation of 4838 metformin users; ${ }^{16} 19 \%$ among 308 hospitalised metformin users in Germany; ${ }^{17}$ and $18 \%$ among 425 general 


\begin{tabular}{|c|c|c|c|c|c|c|c|c|c|c|}
\hline \multirow{2}{*}{$\begin{array}{l}\text { eGFR (using last } \\
\text { creatinine } \\
\text { measurement within } \\
\text { a year before cohort } \\
\text { entry, } \mathrm{mL} / \mathrm{min} / \\
1.73 \mathrm{~m}^{2} \text { ) }\end{array}$} & \multicolumn{5}{|l|}{$\begin{array}{l}\text { Northern Denmark } \\
\text { eGFR }\end{array}$} & \multicolumn{5}{|l|}{$\begin{array}{l}\text { UK } \\
\text { eGFR }\end{array}$} \\
\hline & $\begin{array}{l}\geq 60 \\
(N=20677)\end{array}$ & $\begin{array}{l}45-59 \\
(N=1576)\end{array}$ & $\begin{array}{l}30-44 \\
(N=410)\end{array}$ & $\begin{array}{l}15-29 \\
(\mathrm{~N}=61)\end{array}$ & $\begin{array}{l}<15 \\
(\mathrm{~N}=4)\end{array}$ & $\begin{array}{l}\geq 60 \\
(n=76304)\end{array}$ & $\begin{array}{l}45-59 \\
(n=20648)\end{array}$ & $\begin{array}{l}30-44 \\
(n=4620)\end{array}$ & $\begin{array}{l}15-29 \\
(n=408)\end{array}$ & $\begin{array}{l}<15 \\
(n=12)\end{array}$ \\
\hline \multicolumn{11}{|c|}{ Concurrent antidiabetic drug use $-\mathrm{n}(\%)$ (these are not mutually exclusive categories) } \\
\hline Metformin & $20677(100.0)$ & $1576(100.0)$ & $410(100.0)$ & $61(100.0)$ & $4(100.0)$ & $76304(100)$ & $20648(100)$ & $4620(100)$ & $408(100)$ & $12(100)$ \\
\hline Insulin & $183(0.89)$ & $12(0.76)$ & $5(1.22)$ & $3(4.92)$ & 0 & $1542(2.02)$ & $599(2.90)$ & 195 (4.22) & $25(6.13)$ & 0 \\
\hline Sulfonylureas & $455(2.20)$ & $62(3.93)$ & $21(5.12)$ & $3(4.92)$ & 0 & 12649 (16.58) & $4813(23.31)$ & $1423(30.80)$ & $136(33.33)$ & $5(41.67)$ \\
\hline Glitazones & $7(0.03)$ & 0 & 0 & 0 & 0 & $903(1.18)$ & 276 (1.34) & $74(1.60)$ & $8(1.96)$ & 0 \\
\hline $\begin{array}{l}\text { Other antidiabetic } \\
\text { drugs }\end{array}$ & $34(0.16)$ & $5(0.32)$ & $1(0.24)$ & 0 & 0 & $449(0.59)$ & $142(0.69)$ & $55(1.19)$ & $1(0.25)$ & 0 \\
\hline $\begin{array}{l}\text { Metformin daily dose } \\
(\mathrm{mg}) \text { at cohort entry, } \\
\text { mean }(\mathrm{SD})^{\star}\end{array}$ & $1423.24(2379.07)$ & $1574.50(2999.11)$ & $1395.60(1264.01)$ & $2017.26(2678.15)$ & $793.65(-)$ & $1118.67(430.21)$ & $1070.94(415.64)$ & $1029.79(402.61)$ & $1046.76(385.35)$ & $1045.45(415.60)$ \\
\hline $\begin{array}{l}\text { Metformin daily dose } \\
\text { during follow-up }(\mathrm{mg}) \text {, } \\
\text { mean (SD) }\end{array}$ & $1398.75(543.07)$ & $1282.06(495.61)$ & $1173.55(429.39)$ & $1429.44(548.43)$ & $942.59(256.33)$ & $1294.23(659.96)$ & $1202.78(530.95)$ & $1094.17(584.86)$ & $1097.94(615.96)$ & $1253.35(784.43)$ \\
\hline $\begin{array}{l}\text { Age (years)- } \\
\text { median (IQR) }\end{array}$ & $60(50-67)$ & $72(65-79)$ & $78(72-83)$ & $78(70-86)$ & $65.5(42.5-84)$ & $60(51-68)$ & $71(64-77)$ & 77 (71-82) & $77(72-83)$ & $60.5(53.5,77.5)$ \\
\hline \multicolumn{11}{|l|}{ Age (years)- $n(\%)$} \\
\hline $30-39$ & $1626(7.86)$ & $11(0.70)$ & $1(0.24)$ & 0 & $1(25.00)$ & $4436(5.81)$ & $95(0.46)$ & $8(0.17)$ & $3(0.74)$ & 0 \\
\hline $40-49$ & $3149(15.23)$ & $30(1.90)$ & $3(0.73)$ & $3(4.92)$ & $1(25.00)$ & $11963(15.68)$ & $557(2.70)$ & $40(0.87)$ & $4(0.98)$ & $2(16.67)$ \\
\hline $50-59$ & $5413(26.18)$ & $146(9.26)$ & $13(3.17)$ & 0 & 0 & 20593 (26.99) & 2435 (11.79) & $182(3.94)$ & 15 (3.68) & $3(25.00)$ \\
\hline $60-69$ & $6384(30.87)$ & $439(27.86)$ & $61(14.88)$ & $11(18.03)$ & 0 & $22246(29.15)$ & 6047 (29.29) & 752 (16.28) & $51(12.50)$ & $2(16.67)$ \\
\hline $70-79$ & 3232 (15.63) & $574(36.42)$ & $147(35.85)$ & 18 (29.51) & 0 & $13579(17.80)$ & 7766 (37.61) & 1983 (42.92) & $176(43.14)$ & $3(25.00)$ \\
\hline$\geq 80$ & $873(4.22)$ & $376(23.86)$ & 185 (45.12) & 29 (47.54) & $2(50.00)$ & 3487 (4.57) & 3748 (18.15) & 1655 (35.82) & 159 (38.97) & $2(16.67)$ \\
\hline $\begin{array}{l}\text { Female gender-n } \\
(\%)\end{array}$ & $9050(43.77)$ & 936 (59.39) & 238 (58.05) & $43(70.49)$ & $2(50.00)$ & 29991 (39.30) & $11882(57.55)$ & $3218(69.65)$ & $263(64.46)$ & 7 (58.33) \\
\hline Male gender-n (\%) & $11627(56.23)$ & $640(40.61)$ & $172(41.95)$ & $18(29.51)$ & $2(50.00)$ & $46313(60.70)$ & $8766(42.45)$ & $1402(30.35)$ & $145(35.54)$ & $5(41.67)$ \\
\hline \multicolumn{11}{|c|}{ Duration of type 2 diabetes at cohort entry $\downarrow-n(\%)$} \\
\hline $\begin{array}{l}\text { First prescription at } \\
\text { cohort entry }\end{array}$ & 19855 (96.02) & 1505 (95.49) & $382(93.17)$ & 54 (88.52) & $3(75.00)$ & 14814 (19.41) & $3173(15.37)$ & $701(15.17)$ & $72(17.65)$ & $6(50.00)$ \\
\hline$<1$ year & $51(0.25)$ & $4(0.25)$ & 0 & 0 & 0 & 25724 (33.71) & $5910(28.62)$ & $1142(24.72)$ & $92(22.55)$ & 0 \\
\hline 1 to $>3$ years & $199(0.96)$ & $16(1.02)$ & $3(0.73)$ & $2(3.28)$ & 0 & 14467 (18.96) & 3885 (18.82) & $803(17.38)$ & $54(13.24)$ & $2(16.67)$ \\
\hline$\geq 3$ years & $572(2.77)$ & $51(3.24)$ & $25(6.10)$ & $5(8.20)$ & $1(25.00)$ & $21299(27.91)$ & 7680 (37.19) & $1974(42.73)$ & $190(46.57)$ & 4 (33.33) \\
\hline $\mathrm{HbA} 1 \mathrm{c}$ at cohort entry, & $8.11(1.91)$ & $7.90(1.84)$ & $7.71(1.62)$ & $7.91(1.92)$ & $6.68(1.70)$ & $8.70(1.81)$ & $8.55(1.74)$ & $8.63(1.85)$ & $8.85(2.11)$ & $9.89(4.16)$ \\
\hline \multicolumn{11}{|c|}{ History of potential contraindications for metformin within 5 years before cohort entry $-n(\%)$} \\
\hline Diabetic ketoacidosis & $9(0.04)$ & $1(0.06)$ & 0 & 0 & 0 & $54(0.07)$ & $10(0.05)$ & $4(0.09)$ & $1(0.25)$ & 0 \\
\hline Liver disease & $200(0.97)$ & $10(0.63)$ & $4(0.98)$ & $1(1.64)$ & 0 & $849(1.11)$ & $155(0.75)$ & $26(0.56)$ & $4(0.98)$ & 0 \\
\hline $\begin{array}{l}\text { Alcohol-related } \\
\text { diseases }\end{array}$ & $118(0.57)$ & $8(0.51)$ & $2(0.49)$ & 0 & 0 & $950(1.25)$ & $97(0.47)$ & $20(0.43)$ & $3(0.74)$ & 0 \\
\hline \multicolumn{11}{|c|}{ Co-medication within 90 days before cohort entry- $\mathrm{n}(\%)$} \\
\hline $\begin{array}{l}\text { Other antidiabetic } \\
\text { medications }\end{array}$ & $634(3.07)$ & $73(4.63)$ & $26(6.34)$ & $5(8.20)$ & 0 & $13341(17.48)$ & $5152(24.95)$ & $1506(32.60)$ & $138(33.82)$ & 4 (33.33) \\
\hline NSAIDs & $3424(16.56)$ & $288(18.27)$ & $76(18.54)$ & $13(21.31)$ & $1(25.00)$ & $8855(11.60)$ & 2474 (11.98) & 585 (12.66) & $50(12.25)$ & $1(8.33)$ \\
\hline Antihypertensives & $10454(50.56)$ & $1058(67.13)$ & $313(76.34)$ & 50 (81.97) & $3(75.00)$ & $43595(57.13)$ & $16048(77.72)$ & $4096(88.66)$ & $362(88.73)$ & $11(91.67)$ \\
\hline Aspirin & $807(3.90)$ & $124(7.87)$ & $47(11.46)$ & $3(4.92)$ & $1(25.00)$ & $19181(25.14)$ & $7650(37.05)$ & $1943(42.06)$ & $174(42.65)$ & $6(50.00)$ \\
\hline
\end{tabular}

"Based on non-missing values. $3(4.92)$ 
Table 3 Incidence rate of first decline in eGFR in metformin new users

\begin{tabular}{|c|c|c|c|c|c|c|c|c|}
\hline \multirow[b]{2}{*}{$\begin{array}{l}\text { Baseline } \\
\text { eGFR }\end{array}$} & \multicolumn{4}{|c|}{ Northern Denmark } & \multicolumn{4}{|l|}{ UK } \\
\hline & $\begin{array}{l}\text { N } \\
\text { (denominator) }\end{array}$ & $\begin{array}{l}\text { Count (first } \\
\text { decline in } \\
\text { eGFR) }\end{array}$ & $\begin{array}{l}\text { Person-years } \\
\text { (to first decline } \\
\text { in eGFR) }\end{array}$ & $\begin{array}{l}\text { Incidence rate }(95 \% \mathrm{Cl}) \text {, } \\
\text { per } 100 \text { person-years }\end{array}$ & $\begin{array}{l}\mathrm{N} \\
\text { (denominator) }\end{array}$ & $\begin{array}{l}\text { Count (first } \\
\text { decline in } \\
\text { eGFR) }\end{array}$ & $\begin{array}{l}\text { Person-years } \\
\text { (to first decline } \\
\text { in eGFR) }\end{array}$ & $\begin{array}{l}\text { Incidence rate } \\
(95 \% \mathrm{Cl}) \text {, per } 100 \\
\text { person-years }\end{array}$ \\
\hline Total & 22728 & 3434 & 69792 & 4.92 (4.76 to 5.09$)$ & 101992 & 27325 & 365208 & 7.48 (7.39 to 7.57$)$ \\
\hline$\geq 60$ & 20677 & 2695 & 65088 & 4.14 (3.99 to 4.30$)$ & 76304 & 18936 & 275873 & 6.86 (6.77 to 6.96$)$ \\
\hline $45-59$ & 1576 & 583 & 3857 & $15.12(13.94$ to 16.40$)$ & 20648 & 7089 & 73832 & 9.60 (9.38 to 9.83$)$ \\
\hline $30-44$ & 410 & 143 & 761 & $18.80(15.96$ to 22.15$)$ & 4620 & 1266 & 14637 & 8.65 (8.18 to 9.14$)$ \\
\hline $15-29$ & 61 & 13 & 82 & 15.79 (9.17 to 27.19$)$ & 408 & 34 & 866 & 3.93 (2.76 to 5.42$)$ \\
\hline$<15$ & 4 & & 4 & - & 12 & 0 & 11 & NA \\
\hline
\end{tabular}

eGFR, estimated glomerular filtration rate; NA, not available/applicable.

Table 4 Metformin use after first estimated glomerular filtration rate (eGFR) decline among metformin initiators with first decline that persisted or worsened within 90 days Northern Denmark, N (\%) UK, $\mathbf{N}(\%)$

\begin{tabular}{|c|c|c|c|c|c|c|c|c|c|c|c|c|c|c|c|}
\hline \multirow[b]{2}{*}{$\begin{array}{l}\text { Baseline } \\
\text { eGFR, } \\
\mathrm{mL} / \mathrm{min} / \\
1.73 \mathrm{~m}^{2}\end{array}$} & \multirow[b]{2}{*}{$\begin{array}{l}\text { First } \\
\text { eGFR } \\
\text { decline, } \\
\mathrm{mL} / \mathrm{min} / \\
1.73 \mathrm{~m}^{2}\end{array}$} & \multirow[b]{2}{*}{$\begin{array}{l}\text { Number } \\
\text { of } \\
\text { patients }\end{array}$} & \multirow[b]{2}{*}{$\begin{array}{l}\text { Number } \\
\text { who } \\
\text { continued } \\
\text { use (\%) }\end{array}$} & \multirow[b]{2}{*}{$\begin{array}{l}\text { Number who } \\
\text { discontinued } \\
\text { use }(\%)\end{array}$} & \multirow[b]{2}{*}{$\begin{array}{l}\text { Number } \\
\text { who } \\
\text { switched } \\
\text { use (\%) }\end{array}$} & \multirow[b]{2}{*}{$\begin{array}{l}\text { Metformin } \\
\text { users who } \\
\text { stopped } \\
\text { before } \\
\text { eGFR } \\
\text { decline } \\
\text { (\%) }\end{array}$} & \multirow[b]{2}{*}{$\begin{array}{l}\text { Metformin } \\
\text { users who } \\
\text { stopped } \\
\text { before eGFR } \\
\text { decline but } \\
\text { restarted } \\
\text { after eGFR } \\
\text { decline }\end{array}$} & \multirow[b]{2}{*}{$\begin{array}{l}\text { Incomplete } \\
\text { follow-up: } \\
\text { outcome } \\
\text { unknown }\end{array}$} & & & & & & & \\
\hline & & & & & & & & & $\begin{array}{l}\text { Number } \\
\text { of } \\
\text { patients }\end{array}$ & $\begin{array}{l}\text { Number } \\
\text { who } \\
\text { continued } \\
\text { use (\%) }\end{array}$ & $\begin{array}{l}\text { Number who } \\
\text { discontinued } \\
\text { use (\%) }\end{array}$ & $\begin{array}{l}\text { Number } \\
\text { who } \\
\text { switched } \\
\text { use (\%) }\end{array}$ & $\begin{array}{l}\text { Metformin } \\
\text { users who } \\
\text { stopped } \\
\text { before } \\
\text { eGFR } \\
\text { decline }\end{array}$ & $\begin{array}{l}\text { Metformin } \\
\text { users who } \\
\text { stopped } \\
\text { before eGFR } \\
\text { decline but } \\
\text { restarted } \\
\text { after eGFR } \\
\text { decline }\end{array}$ & $\begin{array}{l}\text { Incomplete } \\
\text { follow-up: } \\
\text { outcome } \\
\text { unknown } \\
(\%)\end{array}$ \\
\hline$\geq 60$ & $45-59$ & 1618 & $1139(70.40)$ & 115 (7.11) & $20(1.24)$ & 236 (14.59) & $80(4.94)$ & $28(1.73)$ & 2460 & $2083(84.67)$ & $160(6.50)$ & 47 (1.91) & $103(4.19)$ & $41(1.67)$ & $26(1.06)$ \\
\hline$\geq 60$ & $30-44$ & 88 & 51 (57.95) & 7 (7.95) & $4(4.55)$ & 14 (15.91) & $3(3.41)$ & $9(10.23)$ & 149 & $107(71.81)$ & $22(14.77)$ & $9(6.04)$ & $6(4.03)$ & 0 & $5(3.36)$ \\
\hline$\geq 60$ & $15-29$ & 8 & 0 & $1(12.50)$ & 0 & $2(25.00)$ & 0 & $5(62.50)$ & 21 & $6(28.57)$ & 7 (33.33) & $3(14.29)$ & 0 & $1(4.76)$ & $4(19.05)$ \\
\hline$\geq 60$ & $<15$ & 3 & 1 (33.33) & $2(66.67)$ & 0 & 0 & 0 & 0 & 2 & $1(50.00)$ & 0 & 0 & 0 & 0 & $1(50.00)$ \\
\hline $45-59$ & $30-44$ & 337 & 239 (70.92) & $29(8.61)$ & $8(2.37)$ & $39(11.57)$ & $12(3.56)$ & $10(2.97)$ & 1414 & $1127(79.70)$ & $144(10.18)$ & $60(4.24)$ & $55(3.89)$ & 19 (1.34) & $9(0.64)$ \\
\hline $45-59$ & $15-29$ & 14 & $3(21.43)$ & $2(14.29)$ & $1(7.14)$ & $1(7.14)$ & $2(14.29)$ & $5(35.71)$ & 46 & 26 (56.52) & $12(26.09)$ & $2(4.35)$ & $3(6.52)$ & 0 & $3(6.52)$ \\
\hline $45-59$ & $<15$ & 0 & 0 & 0 & 0 & 0 & 0 & 0 & 4 & $1(25.00)$ & $1(25.00)$ & $2(50.00)$ & 0 & 0 & 0 \\
\hline $30-44$ & $15-29$ & 77 & 41 (53.25) & 10 (12.99) & $2(2.60)$ & $11(14.29)$ & $5(6.49)$ & 8 (10.39) & 373 & 246 (65.95) & 73 (19.57) & 28 (7.51) & $14(3.75)$ & $7(1.88)$ & $5(1.34)$ \\
\hline $30-44$ & $<15$ & 1 & 0 & 0 & 0 & 0 & 0 & $1(100.0)$ & 4 & $1(25.00)$ & $1(25.00)$ & 0 & 0 & 0 & $2(50.00)$ \\
\hline 15-29 & $<15$ & 8 & $3(37.50)$ & 0 & 0 & $4(50.00)$ & 0 & $1(12.50)$ & 9 & 1 (11.11) & $4(44.44)$ & 2 (22.22) & 2 (22.22) & 0 & 0 \\
\hline
\end{tabular}


population patients with diabetes in Australia. The latter study even found that the proportion of metformin users with renal impairment increased during follow-up. ${ }^{14}$ Our finding that a large proportion of patients continue taking metformin despite renal impairment is also consistent with a US study of 234 patients, reporting that $44 \%$ of patients with eGFR $<60 \mathrm{~mL} / \mathrm{min} / 1.73 \mathrm{~m}^{2}$ continued metformin. ${ }^{13}$

\section{CONCLUSIONS}

Metformin is widely prescribed in patients with mild, but not severe, renal impairment. We observed no dose reduction with decreasing eGFR level at metformin initiation. Among the few metformin initiators with a decline in eGFR to below $30 \mathrm{~mL} / \mathrm{min} / 1.73 \mathrm{~m}^{2}$, a large proportion continued metformin use.

Acknowledgements The authors would like to thank the Pharmacovigilance Working Party (PhVWP) at the European Medicines Agency for helpful comments during the project. They are grateful to Hanne Kjeldahl Schlosser, Helle Vester and Kathleen Jick for outstanding administrative support.

Contributors CFC participated in study conception and design, contributed to data analysis and interpretation, and led the writing. VE and SJ participated in the conception and design of the study, and contributed to data analysis. LL and SS contributed to the design of study and conducted data analyses in CPRD and Denmark, respectively. UH-J conducted data analyses and interpreted the data. HN contributed to study design and provided clinical expertise. HTS oversaw the study, provided clinical expertise, and is responsible for the access to Danish databases. All the authors participated in revisions of the manuscript draft for intellectual content. VE and SJ are the guarantors of this work and, as such, had full access to all the data in the study and take responsibility for the integrity of the data and the accuracy of the data analysis.

Funding This work was commissioned and funded by the European Medicines Agency (Procurement Procedure Number EMA/2013/08/PV). The study received the ENCePP Study Seal.

Competing interests The Department of Clinical Epidemiology is a member of the Danish Center for Strategic Research in Type 2 Diabetes (Danish Research Council, grant no. 09-075724 and 10-079102). Department of Clinical Epidemiology is involved in studies with funding from various companies as research grants to (and administered by) Aarhus University.

Ethics approval In Denmark, the study was approved by the Danish Data Protection Agency (record numbers: 2012-41-0793 and 2013-41-1924). In the UK, ethical approval was obtained from the CPRD's Independent Scientific Advisory Committee.

Provenance and peer review Not commissioned; externally peer reviewed.

Data sharing statement No additional data are available.

Open Access This is an Open Access article distributed in accordance with the Creative Commons Attribution Non Commercial (CC BY-NC 4.0) license, which permits others to distribute, remix, adapt, build upon this work noncommercially, and license their derivative works on different terms, provided the original work is properly cited and the use is non-commercial. See: http:// creativecommons.org/licenses/by-nc/4.0/

\section{REFERENCES}

1. American Diabetes Association. Standards of medical care in diabetes-2015. Diabetes Care 2015;38(Suppl. 1):S5-87.

2. Nathan DM, Buse JB, Davidson MB, et al. Medical management of hyperglycemia in type 2 diabetes: a consensus algorithm for the initiation and adjustment of therapy: a consensus statement of the American Diabetes Association and the European Association for the Study of Diabetes. Diabetes Care 2009;32:193-203.
3. Bodmer M, Meier C, Krahenbuhl S, et al. Metformin, sulfonylureas, or other antidiabetes drugs and the risk of lactic acidosis or hypoglycemia: a nested case-control analysis. Diabetes Care 2008;31:2086-91.

4. Core Safety Profile-Metformin hydrochloride. http://www.bfarm.de/ SharedDocs/Downloads/EN/Drugs/vigilance/PSURs/csp/m-p/ metformin-hydrochloride.html (accessed Jul 2015)

5. Salpeter SR, Greyber E, Pasternak GA, et al. Risk of fatal and nonfatal lactic acidosis with metformin use in type 2 diabetes mellitus. Cochrane Database Syst Rev 2010;(4):CD002967.

6. Eppenga WL, Lalmohamed A, Geerts AF, et al. Risk of lactic acidosis or elevated lactate concentrations in metformin users with renal impairment: a population-based cohort study. Diabetes Care 2014;37:2218-24

7. Inzucchi SE, Lipska KJ, Mayo $\mathrm{H}$, et al. Metformin in patients with type 2 diabetes and kidney disease: a systematic review. JAMA 2014;312:2668-75.

8. Lipska KJ, Bailey CJ, Inzucchi SE. Use of metformin in the setting of mild-to-moderate renal insufficiency. Diabetes Care 2011;34:1431-7.

9. National Institute for Health and Clinical Excellence. The management of type 2 diabetes: 2010 NICE guidelines. 9 March 2015. http://www.nice.org.uk/guidance/cg87/resources/ guidance-type-2-diabetes-pdf (accessed Jul 2015).

10. National evidence based guidelines for blood glucose control in type 2 diabetes. http://www.nhmrc.gov.au/_files_nhmrc/file/publications/ synopses/di19-diabetes-blood-glucose-control.pdf (accessed Jul 2015).

11. Canadian Diabetes Association Clinical Practice Guidelines Expert Committee. Canadian Diabetes Association 2013 clinical practice guidelines for the prevention and management of diabetes in Canada. Can J Diabetes 2013;2013:S1-212.

12. Kosmalski M, Drozdowska A, Sliwinska A, et al. Inappropriate metformin prescribing in elderly type 2 diabetes mellitus (T2DM) patients. Adv Med Sci 2012;57:65-70.

13. Vasisht KP, Chen SC, Peng Y, et al. Limitations of metformin use in patients with kidney disease: are they warranted? Diabetes Obes Metab 2010;12:1079-83.

14. Kamber N, Davis WA, Bruce DG, et al. Metformin and lactic acidosis in an Australian community setting: the Fremantle Diabetes Study. Med J Aust 2008;188:446-9.

15. Warren RE, Strachan MW, Wild $S$, et al. Introducing estimated glomerular filtration rate (eGFR) into clinical practice in the UK: implications for the use of metformin. Diabet Med 2007;24: 494-7.

16. Kennedy L, Herman WH. Renal status among patients using metformin in a primary care setting. Diabetes Care 2005;28: 922-4.

17. Holstein A, Nahrwold D, Hinze S, et al. Contra-indications to metformin therapy are largely disregarded. Diabet Med 1999;16:692-6.

18. Pedersen CB, Gotzsche H, Moller JO, et al. The Danish Civil Registration System. A cohort of eight million persons. Dan Med Bull 2006;53:441-9.

19. Pedersen CB. The Danish Civil Registration System. Scand J Public Health 2011;39(7 Suppl):22-5.

20. Ehrenstein V, Antonsen S, Pedersen L. Existing data sources for clinical epidemiology: Aarhus University Prescription Database. Clin Epidemiol 2010;2:273-9.

21. Grann AF, Erichsen R, Nielsen AG, et al. Existing data sources for clinical epidemiology: the clinical laboratory information system (LABKA) research database at Aarhus University, Denmark. Clin Epidemiol 2011;3:133-8.

22. Lynge E, Sandegaard JL, Rebolj M. The Danish National Patient Register. Scand J Public Health 2011;39:30-3.

23. Jick H, Jick SS, Derby LE. Validation of information recorded on general practitioner based computerised data resource in the United Kingdom. BMJ 1991;302:766-8.

24. Jick SS, Kaye JA, Vasilakis-Scaramozza C, et al. Validity of the general practice research database. Pharmacotherapy 2003;23:686-9.

25. Maahs DM, West NA, Lawrence JM, et al. Epidemiology of type 1 diabetes. Endocrinol Metab Clin North Am 2010;39:481-97.

26. Bronstein J, Tawdekar S, Liu Y, et al. Age of onset of polycystic ovarian syndrome in girls may be earlier than previously thought. $J$ Pediatr Adolesc Gynecol 2011;24:15-20.

27. Gagne JJ, Nelson JC, Fireman B, et al. Taxonomy for monitoring methods within a medical product safety surveillance system: year two report of the Mini-Sentinel Taxonomy Project Workgroup. http://www. mini-sentinel.org/work_products/Statistical_Methods/Mini-Sentinel_ Methods_Taxonomy-Year-2-Report.pdf (accessed Jul 2015). 
28. Kidney Disease: Improving Global Outcomes (KDIGO) CKD Work Group. KDIGO 2012 clinical practice guideline for the evaluation and management of chronic kidney disease. Kidney Int Suppl 2013;3:1-150.

29. Levey AS, Coresh J, Balk E, et al. National Kidney Foundation practice guidelines for chronic kidney disease: evaluation, classification, and stratification. Ann Intern Med 2003;139:137-47.
30. Charlson ME, Pompei P, Ales KL, et al. A new method of classifying prognostic comorbidity in longitudinal studies: development and validation. J Chronic Dis 1987;40:373-83.

31. Thygesen SK, Christiansen CF, Christensen S, et al. The predictive value of ICD-10 diagnostic coding used to assess Charlson comorbidity index conditions in the population-based Danish National Registry of Patients. BMC Med Res Methodol 2011;11:83. 